\title{
STRATEGIC PRICING PRACTICES AND MARKETING PERFORMANCE OF BREWERIES IN SOUTH-SOUTH NIGERIA
}

\author{
Intiedukoba Barry Korubo \\ Department of Management, \\ University of Port Harcourt Business School, \\ Port Harcourt, Rivers State \\ B. Chima Onuoha \\ Department of Management \\ University of Port Harcourt, Choba, \\ Rivers State, Nigeria.
}

\begin{abstract}
The purpose of this study was to examine the effect of strategic pricing/pricing strategies on the marketing financial performance of Beverage firms in South-southern Nigeria. The area of study is Rivers state, while five firms were selected based on convenience. A sample size of 201 respondents was employed. The study employed dimensions of pricing strategy such as; Price skimming, Penetration pricing and Price discrimination and measures such as customer satisfaction. The correlational analysis was employed and indicated that there was a statistically significant and positive relationship between pricing strategies and marketing performance. These results implied that economy pricing has a positive effect on the marketing performance of beverage companies. The study recommends that; Beverage firms should put in place measures to reduce product costs and thus increase marketing performance whenever such a strategy is used. Also, these firms should also adopt ways to implement their pricing strategies better compared to competitor firms. They should undertake market survey when formulating prices for their services. They should identify the prices charged by their competitors in order to come up with prices which are nether too low or very high.
\end{abstract}

Keywords: Strategic Pricing, Marketing Performance, Breweries in South-South Nigeria. 


\section{Introduction}

Price is one of the most versatile components of the marketing mix, which meddles legitimately and in the short term with profitability and its cost adequacy (Simon, Bilstein, \& Luby, 2008). Notwithstanding the significance a price has on organizations' presentation, it seems like such elements have not gotten the best possible consideration by numerous scholastics and marketing experts (Chen, Gao, He, Jiang, and Xiong, 2019). Regularly, in marketing, the principle center is set around improving new items, dissemination channels, and communication channels. As indicated by Okorie and Humphrey (2016), it could prompt encouraged decisions related to price without appropriately assessing the business sector and various cost factors. Subsequently, Pricing is treated as the most straightforward marketing strategy, maybe because numerous organizations decide their prices entirely on instinct and manager's market insight (Simon, 1992). Also, barely any managers deliberately consider Pricing while actively monitoring their prices to make positive conditions making profits (Nagle and Holden, 2003). Liozu and Hinterhuber (2012) feature the requirement for more examination concerning the pricing inclinations and practices. As indicated by the writers, under $2 \%$ of the total distributed articles in the marketing journals are centered around Pricing. Vital Pricing requires a more grounded connection between marketing and different areas of an organization. To upgrade organizations' financial and economic condition, pricing arrangements should be characterized by their inward limits and on the fundamental deliberately comprehension of requirements and wishes of their clients, notwithstanding economic situations, for example, level of competition and economic conditions (Besanko, Dranove, Shanley, \& Schaefer, 2012; De Toni \& Mazzon, 2013).

Globally, there has been a realisation of the impact that pricing strategies have on the product performance. Therefore the pricing strategy adopted has become extremely important in the face of rapid economic and technological changes in which the modern day consumer has become more curious, more educated and conversant with what he/she exactly wants. Nigerians, are not left out, with the advent of the internet, e-commerce and e-shopping allowing consumers to get loads of information about a product both from the manufacturer and external sources. Therefore it is pertinent that companies especially in the beverage industry such as Unilever Nigeria get their pricing strategies right (Kotler \& Armstrong, 2011). Due to the existing argument as to the viability of pricing strategy, it is therefore imperative to know the best strategy amongst the various price strategy alternatives in the beverage firms in Nigeria, especially with regards to Rivers state. To the researcher's knowledge, there is limited number of studies as to the subject matter, which makes it imperative to evaluate the interrelationship between Pricing strategy and Organizational as this constitutes the bane of this study.

\section{Statement of Problem}

Despite the widening demand for beverages in Rivers state and Nigeria as a whole, Okorie and Humphrey (2016) observed that the myriad of macro-economic challenges facing businesses in Nigeria, particularly, the Fast Moving Consumer Goods companies (FMCG), will cause a poor response to many pricing strategies by consumers. Therefore, beverage brands will feel the pinch more with lower profits as consumers look for cheaper brands than quality/differentiated products. This therefore weakens the argument of value based- pricing strategies such as price discrimination and price skimming.

Also, organizations success has been recently hampered in the Nigerian beverage sector which takes the form of rising cost of raw materials which pertains majorly to the beverage firms in 
the nation, accompanying this is the restrictive bans on importation on foreign beverages which has escalated the prices of raw materials to about $45 \%$ of the previous industrial cost (Hussein \& Kachwamba, 2011). This has led to difficult pricing strategy antics in the fragile and growing beverage firms of the nation whose raw materials are largely imported (Okorie \& Humphrey, 2016).

Consequently, majority of these firms (beverage firms) incur high tariff rates, amidst being pushed to scout for alternative sources which appears cumbersome (Saunder\& Cornett, 2014). Also, the nation in line with the above has been plagued with weak output from related agribusiness which is seen to possess insufficient yield. Progressively, the practices of these firms to stay afloat amidst these challenges has involved cutting corners to stay afloat financially which compromises product and output quality.

Simultaneously, beverage firms are faced with unstable power supply and health and hygiene standards needs coupled with taxation and undue interferences by local, state and federal government which needs to be addressed (Odumodu, 2012). These has led to the failure of many beverage sector and has such constitute the bane of this study. Despite the gained prominence of Pricing strategy, the interrelationship between Pricing strategy and Improved performance in organizations has been frequently discussed, to which some researchers and scholars like Eskidson (1994) and Harari (1997) claimed that Pricing strategy Programme are ineffective or not very efficient in most studied organizations. Judging by the aforementioned, it becomes imperative to evaluate the influence of pricing strategy on Marketing performance especially in a nation like Nigeria to ascertain its extent of relationship.

The aim of this study is to identify the relationship between Pricing strategy and Marketing performance in beverage firms in Rivers State; while the Objectives include:

i. To examine the influence of Price skimming on Customer Satisfaction of beverage firms in Rivers State.

ii. To estimate the influence of Penetration pricing on Customer Satisfaction of beverage firms in Rivers State.

iii. To examine the influence of between Prices discrimination on Customer Satisfaction of beverage firms in Rivers State.

iv. To ascertain the extent to which Organizational culture moderates the relationship between Pricing strategy and Marketing performance in Rivers state.

\section{Research Hypotheses}

The proposed research work will be guided by the following hypotheses stated in their null form:

$\mathbf{H}_{\mathbf{0 1}}$ : There is no significant relationship between Price skimming and Customer Satisfaction of Beverage Organizations in Rivers State.

$\mathbf{H}_{\mathbf{0 2}}$ : There is no significant relationship between Penetration pricing and Customer Satisfaction of Beverage Organizations in Rivers State.

$\mathbf{H}_{\mathbf{0 3}}$ : There is no significant relationship between Price discrimination and Customer Satisfaction of Beverage Organizations in Rivers State. 
$\mathbf{H}_{\mathbf{0 4}}$ : Organizational culture does not moderate the relationship between Price discrimination and Customer Satisfaction of Beverage Organizations in Rivers State.

The result of this work shall be of immense assistance to management in organizations as this will assist them in understanding the vital role and effect of pricing strategy and its ability to foster marketing performance and how its appropriate types and dimensions can be adopted to educating management and employees towards better and efficient activities and decision making thereby providing better incentives towards performance improvement.

This study will be limited to the three key dimensions adapted despite the wide array of dimensions as well as the adapted measures for marketing performance. These are the four basic strategies, variations of which are used in the industry. Apart from the four basic pricing strategies -- premium, skimming, economy or value and penetration -- there can be several other variations on these. But the study will limit pricing strategies to only three which are; Price skimming, price penetration and price discrimination. This study will be limited to selected beverage firms in Port-Harcourt. The unit of analysis for this study is the organizational level.

\section{Literature review}

\subsection{Theoretical Framework}

The baseline theories of this study will be drawn from the Dynamic Capability Theory presented below as follows.

\subsubsection{Theory of Price}

The theory of price as developed by Donald in 1985 is a theory that states that the price for any specific good or service is based on the relationship between its supply and demand. The optimal market price, or equilibrium, is the point at which the total number of items available can be reasonably consumed by potential customers. When the relative price of something goes up the quantity demanded of that thing will go down. It does not mean that the cheaper goods will be demanded nor does it say that changes in dollar prices change what is demanded (Donald, 1985). The income and prices that consumers face limit their choices, but within these limits the exact amounts of goods (or bads) they choose are a matter of taste (Donald, 1985). A consumer's taste for two goods such as a guitar lessons and beer can be described as a hill of utility (Donald, 1985). It is not always true that subsidies to a price or gifts of goods increase the amount consumed (Donald, 1985).The way in which a consumer facing the usual offer reacts to a fall in price splits naturally into two parts. On the transport axis, the substitution effect is the move from a relatively lower price to a higher price, the substitution effect is the move from the start to the free point, the income effect being the move from the free point to finish (Donald, 1985). The real point is that the increase in transport for example bought after a fall in price depends on two features of consumer's indifference map (Donald, 1985). It depends, first on how sensitive he is at a given real income to changes in price, the substitution effect that is how great the curvature of an indifference curve (Donald, 1985) is. Secondly, depends on how sensitive he is at a given price to changes in real income, the income effect that is how much more transport he buys as he moves up to the higher indifference curve (Donald, 1985). 


\subsection{Conceptual Framework}

To implement this study on pricing strategy and marketing performance in Beverage firms in Rivers State: the following Dimensions (Independent) and Measures (Dependent variables) are shown in a conceptual form.

\section{Pricing Strategy}

As per Monroe (2003), pricing decisions are very important decisions of the company since it influences income and the organizations' return and provides a competitive edge over the competitors. Along these lines, the undertaking of creating and characterizing prices is intricate and testing because the managers engaged with this cycle must see the perception of the price in the eyes of customers, how to build up the apparent value, and what characteristic are and pertinent costs to follow this need, as consider the estimating goals of the organization and their serious situation in the market. In this way, Nagle and Hogan (2007) contend that organizations which don't deal with their prices generally lose power over them, disabling their income and cost adequacy essentially because of the customers will depend on addressing a fixed cost, which also of that it depends on apparent value, yet additionally relies upon the prices decided by the main rivals. Therefore, mixed up or inexistent pricing approaches could lead purchasers to expand the volume of data while permitting them to increase their dealing power hence compelling price decreases and limits. The difference between customary price setting and strategic assessing involves on setting prices by reacting to the market conditions or directing them adequately, being their sole motivation to apply the most beneficial assessing by making more an incentive for clients without the dedication of growing the business volume (Nagle and Holden, 2003) Logically, there is genuinely not a novel way at portraying costs. Before setting a price, the association must pick the system for the thing despite the proposed focuses, since the more clear these choices, the more straightforward it will be to develop prices (Hinterhuber and Liozu, 2013). According to Hinterhuber (2008), prices exceptionally influence associations' gainfulness and assessing methodology change widely among parts and market conditions. Regardless, researchers, for the most part, agree that assessing frameworks can be grouped in three significant social occasions: cost-based assessing, contention-based esteeming, and customer esteem based esteeming (Nagle and Holden,2003).Nagle and Holden (2003) fight that there must be a sensible idea of information, perception, and common direct of the 3C's of this cycle (Cost, Competition, and Customers) to deal with show up at the ideal price. The organization of such information is an important factor for the accomplishment of the assessing definition procedure and the price settlement. Now and again, these practices have similarly been allocated as assessing methodologies (Avlonitis, Indounas, and Gounaris, 2005).

\section{Dimension of Pricing strategy}

The study proceeds to evaluate the various dimensions and measures of Pricing strategy which includes those captured and not captured in the scope of the study and are presented as follows:

Price skimming: is a product pricing strategy by which a firm charges the highest initial price that customers will pay. As the demand of the first customers is satisfied, the firm lowers the price to attract another, more price-sensitive segment. High price is charged for a product till such time as competitors allow after which prices can be dropped. The idea is to recover maximum money before the product or segment attracts more competitors who will lower profits for all concerned. Besanko and Winston (2000) found that central assumption of price skimming is because each consumer pays a price at or below his or 
her reservation price, each consumer is satisfied with his or her purchase. However, beyond the purchase decision, there is scant research on consumers' responses to price skimming. Instead, investigations concern firm profit maximization and variables impacting profit maximization, such as diffusion rates, competition and production learning curves (Robinson and Lakhani 2005; Irwin and Klenow, 2004). Thus, although price skimming is widely used by managers and investigated in the economics and strategy literatures, it has received little attention in consumer research.

- Penetration pricing: is a pricing strategy where the price of a product is initially set low to rapidly reach a wide fraction of the market and initiate word of mouth. The strategy works on the expectation that customers will switch to the new brand because of the lower price. Here, price is set artificially low to gain market share quickly. This is done when a new product is being launched. It is understood that prices will be raised once the promotion period is over and market share objectives are achieved. Henard (2001) observed that the penetration price strategy is realized by setting a relatively low price for the new product aiming at reaching deeper market penetration in the current period and providing, as well as, a greater market share in subsequent periods. This strategy is applied only in the case when the price of demanded product is at the level which provides a sales volume increase. Therefore, in an industry where the considerable part of total costs could be reduced thanks to the economies of scale and experience, the justified penetration pricing application enables the company to realize greater a profit in the market.

Price Discrimination: is a selling strategy that charges customers different prices for the same product or service based on what the seller thinks they can get the customer to agree to. In pure price discrimination, the seller charges each customer the maximum price he or she will pay. In this strategy, high price is used as a defining criterion. Such pricing strategies work in segments and industries where a strong competitive advantage exists for the company. The earliest efforts to identify the relationship between pricing of risk and the profitability of beverage companies can be attributed to Bain (2001) who developed the concentration profit hypothesis.

\section{Concept of Marketing performance and Performance}

Marketing performance can be judged by many different constituencies, resulting in many different interpretations of successful performance. Each of these perspectives of marketing performance can be argued to be unique (Robert, 2004). Performance management can take many forms from dealing with issues internal to the organization to catering to stakeholders or handling issues in its environment. Performance management involves the use of both quantitative and qualitative techniques and paying due attention to the human (behavioral) side of the enterprise (Arie, 2005). Any organization should target the ideal standard of success namely: consistently competent, ethical, and energetic behavior that always succeeds in producing the best results (Gary, 2003). One of the main elements to achieve an effective organisational management processes is the performance/success measurement. The performance of one organisation can be directly related to its ability to achieve their strategic and financial objectives ( $\mathrm{Li}$ et al., 2006). The performance of organizations was largely neglected in past research, whereas some other (Katou, 2008) who were discussing the organizational performance with reference to the financial performance only. Stock et al. (2000) were also discussing the organizational performance through measuring both financial and market harmonic performance which includes the return on investment measures (ROI), sales profit and growth and market share progress. 


\section{Measures of Marketing performance}

\section{Customer Satisfaction}

Rai (2013) defined satisfaction as “a buyer's emotional or cognitive response post-subjective assessment and comparison of pre-purchase expectations and actual performance subsequent to the consumption of the product or service, meanwhile evaluating the costs incurred and benefits reaped in a specific purchase even or over time in course of transacting with an organization".

Most recent studies emphasize the importance of customer satisfaction, like (Asikhia, 2010; Kassim \& Abdullah, 2010), who showed that the customer satisfaction is a vital trend to develop the organizational performance, Fotopoulos and Psomas's (2010) study also reflects that Price discrimination and satisfaction are positively and significantly related to the performance of the organization, while Chen et al.(2012) confirmed that well-established relationship with customers can increase both financial and nonfinancial performance. Dadfar et al. (2013) reveals that it is important to build a strong relationship with the customer and service provider in order to be able to have an efficient co-production together.

\section{Conceptual Framework}

To successfully evaluate this study on Pricing strategy and Marketing performance in Beverage firms in Rivers State: the following Dimensions (Independent) and Measures (dependent variables) are shown in a conceptual form. The following framework displays three key variables which includes the predictor variable; Price skimming, Penetration pricing and Customer Relation as they relate with the measures of Marketing performance which comprise of Customer satisfaction as shown below:

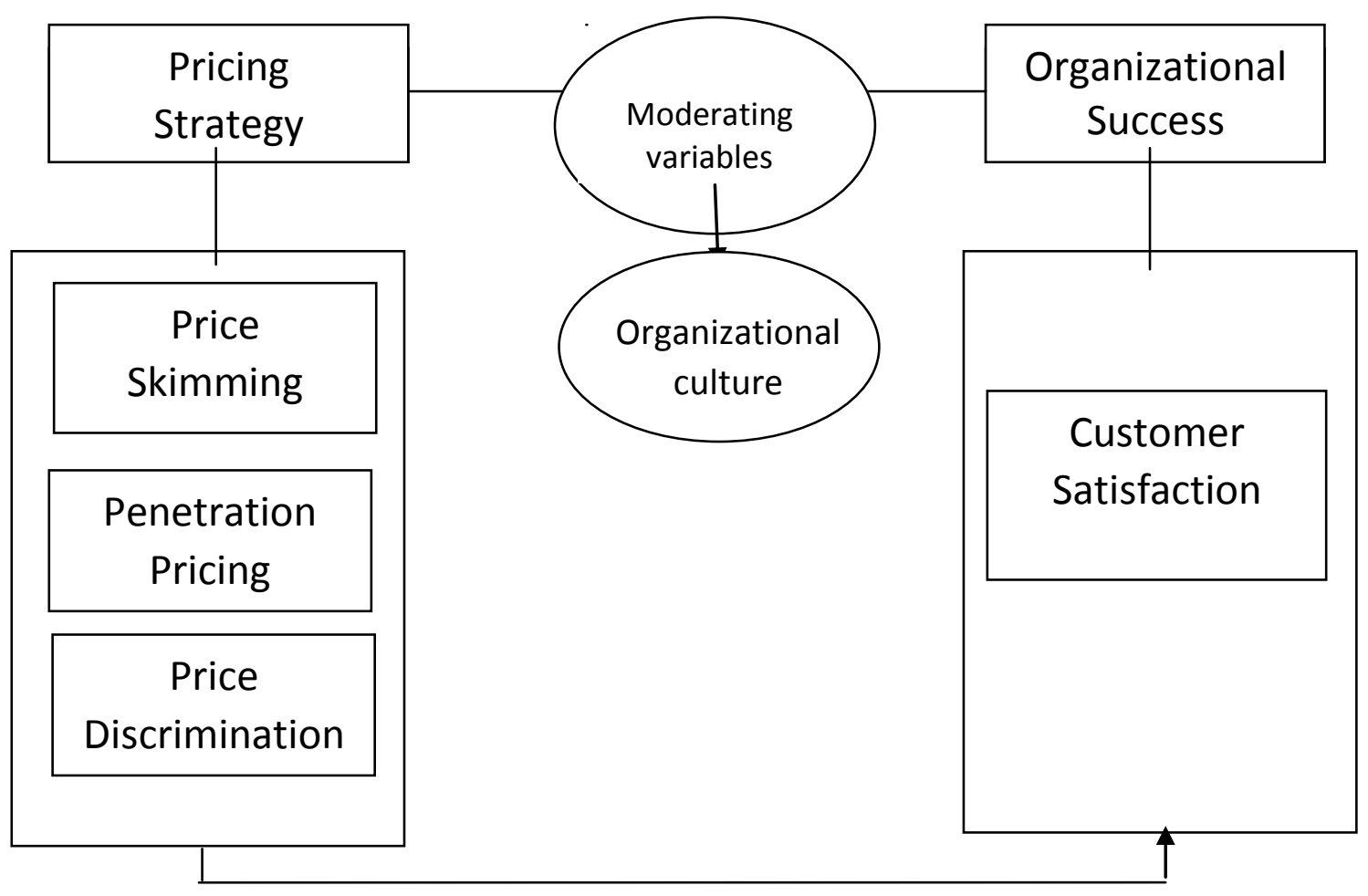

Source: Nyaga and Muema (2017); Hsieh, Yang and Fu (2011). 
The Dimensions which represents the independent variables (Pricing strategy) were adapted in line with the work of Nyaga and Muema (2017) while the measures representing the dependent variables (Marketing performance) were adapted from the work of Hsieh, Yang and Fu (2011).

The Operational framework comprises of three key variables which includes the predictor variable; Price skimming, Penetration pricing and Customer Relation in relation to the measures of Marketing performance which entails Customer satisfaction are as shown below:

\subsection{Empirical Review}

To sufficiently identify the expected relationship of the subject matter, the following literatures are evaluated as follows;

Nafuna, Ayub, Tumwine, Watundu, Bonareri, and Nakola (2019) examined the mediating effect of Competitive advantage on the relationship between Pricing strategies and financial performance in private primary schools of Uganda. The research adopted the Med Graph program and Sobel tests for the mediation effects so as to develop a closed loop model of financial performance of private primary schools. The study is based on a quantitative approach and cross sectional Research design. Descriptive statistics and inferential statistics were used in the analysis. The results reveal that that competitive advantage partially mediates the relationship between pricing strategies and financial performance (partial mediation). The study makes a contribution by providing information that is relevant for filling the practical gap that exists in financial performance of private primary schools in the settings of developing countries as well as contributing to the theoretical development of pricing strategies. Practical implications of the paper puts it that in order to have a meaningful interpretation of the results of the relationships between study variables, it is always vital to assess the role of the mediator in the relationship.

Nyaga and Muema (2017) examined the economy, skimming, penetration and premium pricing strategies on the profitability of insurance firms in Kenya. The descriptive research design was employed by the study. The population of study was the 45 insurance companies operating in Kenya as at 31st December 2012. Data was drawn from a period of five (5) years that is 20082012. The sample of this study was $10 \%$ of the sales workforce which comprised of 900 employees from the 45 insurance companies. The sample was generated by purposively sampling two employees from each insurance company. The researcher collected primary data with the help of a questionnaire. The primary data obtained from the questionnaires was summarized and analyzed by use of descriptive and inferential statistical techniques. Correlation results indicated that there was a statistically significant and positive relationship between economy pricing, skimming pricing, penetration pricing, premium pricing, price optimization strategies, strategies and profitability. Results show that economy pricing, skimming pricing, penetration pricing, premium pricing, price optimization strategies have a positive effect on the profitability of insurance companies. The correlation between profitability and penetration, premium and price optimization strategies was strong and positive. The regression results indicate that the variables; economy pricing, penetration pricing, premium pricing, price optimization strategy and skimming pricing were satisfactorily explaining profitability. The study recommends that insurance companies put in place measures assess the most effective pricing strategy to reduce product costs and thus increase profitability whenever such a strategy is used.

Oke, Olarewaju, and Ayooluwade (2016) examined the relevance of pricing strategies on the corporate performance of brewery industry in Nigeria for the period 2005-2013. The study 
adopted descriptive research design and the secondary data gathered from the quoted brewery industries was analysed using panel data regression model. The result revealed that pricing strategies have a great influence on the performance of brewery as it was showed that 91 percent in the performance of the industry can be explained by the pricing strategy. This further revealed the degree or extent to which both variables are correlated. However, the adopted sales strategy was revealed to be negatively related to the performance of the brewery industry in Nigeria as its limitation was showed from the level of net revenue of the industries. This negative effect was more visible in International Brewery as revealed by the fixed effect panel model. Thus, this study concluded that brewery industry should adopted a value based communication to bridge the communication gaps between the sales and marketing unit that caused the impact of sales growth on the net revenue to be negative; effective market segmentation must be encouraged in order to boost the sales growth that can lead to enhanced and improved revenue generation; effective cost and discounting system should be adopted to attract more customers under the condition that product quality will not be compromised.

Sije and Oloko (2013) examined the relationship between penetration pricing strategy and the performance of the SMEs in Kenya. The population for this study consisted of members of staff of selected SMEs in Kenya. Stratified random sampling was used in the study where members of staff from various SMEs were selected and issued with questionnaires. Primary data collection instrument that was used was questionnaire. The data collected was then analyzed by both descriptive and inferential statistical tools and the information generated was presented in form of figures and tables. The researcher found out that there was strong positive correlation between penetration pricing strategy and performance. The researcher therefore concluded that the enterprises should focus more of its effort on penetration pricing strategy because there was a significant level of effect of penetration pricing strategy on the number of customers, customer loyalty and quality of goods and service.

\section{METHODOLOGY}

For the purpose of this study, The Cross-Sectional Survey design will be utilized which is an aspect of the Quasi-experimental research design as it seeks to evaluate multiple variables at a single time period. The Accessible population will comprise of all 17 Beverage firms in Rivers state as stated by the Federal Ministry of Industries in Nigeria (Directory.org.ng, 2020). Due to the strategic nature of pricing in firms, only management staff qualify as respondents in the study. This would entail top, middle and lower level managers. The accessible population (via mail due to the Covid-19 pandemic) is five of the registered beverage firms as listed below as follows. 
Table 3.1: Accessible Firms by mail

\section{S/N Firm Address}

1 Pokobros Foods \& Chemical Plot Pl Harbour Ind Layout Off Atani Road Port Industries Limited Harcourt Rivers

2 Dictachi Foods Nig. Ltd. $\quad$ Plt. 2 Dictachi Lane, Off J.C Str., Off Peter Odili Rd., Trans Amadi, P/H Rivers State

\section{Cashewfield Nigeria Limited No 122 Okpara Road, Okigwe Imo State Nigeria \\ 4 7-Up Bottling Co. Plc No 247, MoshoodAbiola Way, Ijora, Apapa, Lagos. \\ 5 3nity Foods 29 Wogu Street D Line, Port Harcourt, Rivers State.}

Source: Federal Ministry of Industries (2020) Accessed on the $11^{\text {th }}$ of April 2020 from https://www.directory.org.ng/listcompany-food_processing_companies?in=rivers

Due to firm repository, all employed firm has management staff (top, middle and lower level managers) totaling 588 as presented in the table below, these firms were selected using the following attributes;

This study will adopt the purposive sampling technique as predicated on the author's convenience. The sample size will be determined using the Taro Yamane formula at a 0.05 level of significance I.e. 95\% confidence level. The Taro Yamane Formular is shown as:

$$
\begin{aligned}
& \mathrm{n} \quad=\frac{588}{1+588(0.05)^{2}} \\
& \mathrm{n}=238.05=238 \text { sample }
\end{aligned}
$$

Which indicates that 238 questionnaire will be distributed as deciphered above.

This validity came via the pilot testing which was carried out using 2 academic staffs in the University of Port Harcourt, and involved a miniature statistical analysis, towards testing the sufficiency of the dimensions and measures as it pertains to the underlying topic, Their response led to the modification of some items prior to the administration to the respondents,

The reliability of the instrument utilized in this study as displayed by the Cronbach alpha is 0.992, which shows a significant reliability on the research questions as each question displayed a high degree of reliability as shown in the appendix.

\section{Data Analysis Technique}

This refers to the statistical tools to be utilized in the analyses and interpretation of the questionnaire as regards the hypotheses. The Spearman's rank order correlation coefficient will be used to analyse the data obtained from the questionnaire which will enable the researcher examine the relationship between Pricing strategy and Marketing performance. All Statistical analysis will be carried out using the Statistical Package for Social Sciences (SPSS) version 22.

Decision Criteria: for Spearman's rank order correlation coefficient is:

Reject null hypothesis if Spearman's rho coefficient is greater than critical value (CV) 
Reject null hypothesis if Spearman's rho coefficient is smaller or equals to critical value

\section{Criteria}

$\mathrm{r}_{\mathrm{s}}>\mathrm{CV}$

$\mathrm{r}_{\mathrm{s}} \leq \mathrm{CV}$

\section{Decision}

Reject the null hypothesis

Fail to reject the null hypothesis.

\section{Results and Discussion}

The table below explains all the variables used in our analysis. It also summarises the central measures of all the variables that we can generalize to get the overall picture of the Brewery Industry in South-Nigeria. A total of four hypothesized bivariate associations was postulated in the study; all stated in the null form of no association. Data in this section is analyzed using the spearman rank order correlation coefficient at a 95\% confidence interval. Analysis is based on a significant criterion of 0.05 for the acceptance $(p>0.05)$ or rejection $(p<0.05)$ of the null hypotheses.

\section{Table 4.3.1 Spearman Correlation Matrix}

\section{Correlations}

\begin{tabular}{|c|c|c|c|c|c|c|}
\hline & & & $\begin{array}{c}\text { Price } \\
\text { skimming }\end{array}$ & $\begin{array}{c}\text { Penetration } \\
\text { pricing }\end{array}$ & $\begin{array}{c}\text { Price } \\
\text { discriminati } \\
\text { on }\end{array}$ & $\begin{array}{c}\text { Customer } \\
\text { Satisfactio } \\
n\end{array}$ \\
\hline \multirow{12}{*}{$\begin{array}{l}\text { Spearman } \\
\text { 's rho }\end{array}$} & \multirow{3}{*}{ Price skimming } & $\begin{array}{l}\text { Correlation } \\
\text { Coefficient }\end{array}$ & 1.000 & .889 & .617 & .801 \\
\hline & & Sig. (2-tailed) & & .000 & .000 & .000 \\
\hline & & $\mathrm{N}$ & 201 & 201 & 201 & 201 \\
\hline & \multirow{3}{*}{$\begin{array}{l}\text { Penetration } \\
\text { pricing }\end{array}$} & $\begin{array}{l}\text { Correlation } \\
\text { Coefficient }\end{array}$ & $.889^{\pi *}$ & 1.000 & $.849^{x \pi}$ & $.936^{\pi x}$ \\
\hline & & Sig. (2-tailed) & .000 & . & .000 & .000 \\
\hline & & $\mathrm{N}$ & 201 & 201 & 201 & 201 \\
\hline & \multirow{3}{*}{$\begin{array}{l}\text { Price } \\
\text { discrimination }\end{array}$} & $\begin{array}{l}\text { Correlation } \\
\text { Coefficient }\end{array}$ & $.617^{\mathrm{x}}$ & $.849^{x \pi}$ & 1.000 & $.841^{\pi \times}$ \\
\hline & & Sig. (2-tailed) & .000 & .000 & . & .000 \\
\hline & & $\mathrm{N}$ & 201 & 201 & 201 & 201 \\
\hline & \multirow{3}{*}{$\begin{array}{l}\text { Customer } \\
\text { Satisfaction }\end{array}$} & $\begin{array}{l}\text { Correlation } \\
\text { Coefficient }\end{array}$ & $.801^{n}$ & $.936^{\wedge}$ & $.841^{\prime \prime}$ & 1.000 \\
\hline & & Sig. (2-tailed) & .000 & .000 & .000 & . \\
\hline & & $\mathrm{N}$ & 201 & 201 & 201 & 201 \\
\hline
\end{tabular}

**. Correlation is significant at the 0.05 level (2-tailed).

Source: Research data, 2020 (SPSS-25 output) 
Partial Correlation (Moderating Role of Organizational culture).

\section{Correlations}

\begin{tabular}{|lll|r|r|}
\hline Control Variables & & $\begin{array}{c}\text { Marketing } \\
\text { performance }\end{array}$ & Pricing strategy \\
\cline { 2 - 4 } & Marketing & Correlation & 1.000 & -.074 \\
Organizational & performance & Significance (2-tailed) &. & .488 \\
culture & & $\mathrm{df}$ & 0 & 88 \\
& & Correlation & -.074 & 1.000 \\
& Pricing strategy & Significance (2-tailed) & .488 &. \\
& & $\mathrm{df}$ & 88 & 0 \\
\hline
\end{tabular}

Source: Research data, 2020.

Judging by the output in table 4.22 above, it could be derived that Organizational culture exhibits no moderating influence on the relationship between Pricing strategy and Marketing performance in the employed institution based on the correlation coefficient of -.074 at a probability level of 0.488 which is greater than the significance level of $0.05(5 \%)$, therefore we do not reject the null hypothesis and conclude that There is no significant influence of Organizational culture on the association between Pricing strategy and Marketing performance of Beverage firms in Rivers State

\section{Summary of Findings}

In summary, this study discovered that

i. Price skimming illustrates a positive and significant relationship with Customer Satisfaction of Organizations in Port Harcourt.

ii. Penetration pricing demonstrates a positive and significant relationship with Customer Satisfaction of Organizations in Port Harcourt.

iii. Price discrimination shows a positive and significant relationship with Customer Satisfaction of Organizations in Port Harcourt.

iv. Organizational culture does not moderate the relationship between Pricing strategy and Marketing performance in organizations.

\section{Discussion of findings}

Based on the above findings, the study realizes;

Despite the inherent importance of Pricing strategy, it has rarely been adopted by the managers, usually as a result of their gender as all sample managers were largely male, and majority of the managers had a strong knack for Penetration pricing and were mostly weak towards Price skimming which could also be attributed to their marital status as most of the respondent were married and might have maintained a stringent workplace behaviour due to their level of responsibility in and out of their respective workplace, A positive and significant relationship was fund amongst employed variables showing that a rise in any of the Pricing strategy is very likely to give birth to a corresponding rise in their Marketing performance status and a drop in the Pricing strategy is more likely to result to a decreased level of Marketing performance as verified by the analytical result based on the employed instrument (questionnaire), in this light, it can be seen that managers as attached to the Respondents for the sake of this study gave little to no room for a wide range of pricing strategy and carefully averted it due to the inherent managerial problem attached to being too loose with the 
employees while the few who strongly took to pricing strategy displayed a lower degree of Marketing performance.

This study bears credence to similar work like Lee (2010), Savage (2007), Field (2009), Zeynep (2014), Brian and Vivona, 2014 who similarly found a positive and significant relationship between Pricing strategy and Marketing performance, although it has a resemblance of Mkenzie (2009) work who found a significant relationship, but unlike this that study, this study only found a poor level of Pricing strategy in employed institutions within the geographical terrain of the study.

\section{CONCLUSION AND RECOMMENDATION \# Conclusions}

Based on the objectives and the findings of the study the following conclusion can be made; It can also be concluded that pricing was a strong determinant of beverage company's marketing performance. It was also possible to conclude that the beverage companies had put in place effective skimming pricing practices as they helped them to recover cost quickly enabling firms to have substantial lead in competition with both new and established products were in a better position to adopt skimming pricing. The study noted that skimming had a positive effect on marketing performance of beverage companies. Penetration pricing was a strong determinant of beverage company's marketing performance. This was concluded because beverage companies had put in place effective penetration pricing practices which enabled them secure a wide market acceptance hence a bigger customer base and also the strategy helped them discourage competition in that it focused more on acceptance rather than profits. It can be concluded that firms had successfully adopted effective price discrimination strategies in the recent years and strategies had yielded more sales in their beverage products. The price optimization strategies had a positive effect on marketing performance of beverage companies and were a key determinant of the beverage companies' performance. It can be concluded that beverage companies had put in place effective price optimization strategies in that they used price increases and decreases to achieve price optimization of the everyday business. This had led to increase in sales and consequently increased returns in terms of profits. The study further noted that price optimization strategies had a positive effect on marketing performance of beverage companies.

\section{Recommendations}

From the findings of the study, it is therefore recommended that:

i. Beverage firms put in place measures assess the most effective pricing strategy to reduce product costs and thus increase marketing performance whenever such a strategy is used.

ii. Beverage firms should also adopt ways to implement their pricing strategies better compared to competitor firms. They should undertake market survey when formulating prices for their services. They should identify the prices charged by their competitors in order to come up with prices which are nether too low or very high.

Beverage firms should also ensure that the strategies they adopt help them discourage competition and focus more on both acceptance and profits. 


\section{References}

Arie, H. (2005). Performance Measurement is only one way of Managing Performance, International Journal of Productivity and Performance Management, 54(7).

Asikhia, O. (2010). Customer orientation and firm performance among Nigerian small and medium scale businesses. International Journal of Marketing Studies, 2(1), 197-205.

Bain, J.S. (2001).Relation of Profit Rate to Industry concentration: American manufacturing, 1936 - 1940, Quarterly Journal of Economics, 65: 293-324.

Bernays, E. L. (1955). The theory and practice of public relations: A resume. In E.L. Bernays (ed), the engineering of consent (pp. 3-25). Norman, OK: University of Oklahoma Press.

Besanko, D., \&Wayne, L. W. (2000).Optimal Price Skimming by a Monopolist Facing Rational Consumers.Management Science 36 (5):555-567.

Brassington, F., \& Pettitt, S. (2000), Principles of marketing. 2nd Edition, Harlow Pearson Education Limited.

Chen, T., Gao, Z., He, J., Jiang, W., \&Xiong, W. (2019). Daily price limits and destructive market behavior. Journal of econometrics, 208(1), 249-264.

Chiliya N., Herbst G., \& Roberts- Combard. M, (2009). The impact of marketing strategies on profitability of small grocery shops in South African Townships. African Journal of Business Management 3 (3) 70 - 79.

Dadfar,H., Staffan, B., Sedigheh,S., \&Ebadzadeh, S. (2013). Customer involvement in service production, delivery and quality.International Journal of Quality and Service Sciences, $5(1), 46-65$

Demirhan, H. G., \& Anwar, W. (2014). Factors affecting the financial performance of the firms during the financial crisis: Evidence from Turkey. EgeStratejikAraştırmalarDergisi, 5(2), 65-80.

Din, M. U., Ghani, E., \& Mahmood, T. (2007). Technical efficiency of Pakistan's manufacturing sector: A stochastic frontier and data envelopment analysis. The Pakistan Development Review, 46(1), 1-18.

Donald, N. M. (1985). The Applied Theory of Price, Macmillan, 6-330.

Eljelly, A. M. (2004). Liquidity-profitability tradeoff: An empirical investigation in an emerging market. International Journal of Commerce and Management, 14(2), 48-61.

Flanagan, R., \& Norman, G. (2006).Pricing Policy, in Hillebrandt, P.M., \& Cannon J. (eds), The Management of Construction Firms - Aspect of Theory, Macmillan, pp. 129-153

Fotopoulos, C. V., \&Psomas, E.L. (2010). The structural relationships between pricing strategy factors and organizational performance. The pricing strategies Journal, 22(5), 539-552.

Gary, B. (2003). Blending "we/me" in Performance Management. Team Performance Management, 9(7/8).

Gary, B. (2003). Blending "we/me" in Performance Management. Team Performance Management, 9 (7/8). 
Gu, F. F., Kim, N., Tse, D. K., and Wang, D. T. (2010). Managing Distributors' Changing Motivations Over the Course of a Joint Sales Program. Journal of Marketing,74(5), 3247.

Haberberg, A., \&Rieple, A. (2008).Strategic Management Theory and Application. Oxford University Press.

Harari, O. (1997). Ten reasons why PRICING STRATEGIES doesn't work. Management Review. 86(1). 38-44.

Hussein A., \&Kachwamba M. (2011). Low Quality products in Developing Countries' Markets: Is it one of Globalization Challenges? International Review of Social Sciences and Humanities. 26-36.

Irwin, D. A.\& Peter, J. K. (2004). Learning-by- Doing Spillovers in the Semiconductor Industry. Journal of Political Economy 102:1200-1227.

Katou, A. (2008). Measuring the impact of HRM on organisational performance, Journal of industrial engineering and management, doi:10.3926/jiem.2008.v1n2.p119-142.

Kotler, P., \& Keller, L. (2009). Marketing Management (13th ed.). Pearson International.

Levine S., (2006), High performance organizations: creating a culture of agreement. Handbook of Business Strategy, pp. 375-380.

Myers, M. B., Cavusgil, S. D. and Diamantopoulos, A. (2002). Antecedents and actions of export pricing strategy: a conceptual framework and research propositions. European Journal of Marketing,36(1/2), 159-188.

Nyaga, P. K., \&Muema, M. W. (2017). An analysis of the effect of pricing strategies on profitability of insurance firms in Kenya. International Journal of Finance and Accounting, 2(3), 44-65.

Odumodu J. (2012). Nigeria is being de-industrialized, under siege of substandard products. Available at http://www.vanguardngr.com/2012/02/nigeria-is-being-de-industrializedunder-seige-ofsubstanard-products/\#sthash.tRSXDURK.dpuf

Oke, M. O., Olarewaju, O. M., \&Ayooluwade, E. (2016). The relevance of pricing strategies on corporate performances in Nigeria. International Journal of Economics, commerce and management, 4(1), 475-488.

Okorie, A., \& Humphrey, A. (2016). Standards Organization of Nigeria and Funding Challenges to Quality Control. Mediterranean Journal of Social Sciences, 7(5), 67.

Rai, A.K. (2013).Price discriminationhip management: Concepts and cases(2nd ed.).New Delhi: PHI Learning.

Robert, B. (2004). Measuring Organizational Performance: an exploratory study.

Robinson, B., \& Lakhani, L. (2005).Dynamic Price Models for New-Product Planning.Management Science 21 (10):1113-1122.

Sije, A., \&Oloko, M. (2013). Penetration pricing strategy and performance of small and medium enterprises in Kenya. European Journal of Business and Social Sciences, 2(9), $114-123$. 
International Journal of Advanced Academic Research (Business and Economic Development) | ISSN: 2488-9849

Journal DOI: 10.46654/ij.24889849

Vol. 6, Issue 12 (December, 2020) | www.ijaar.org

Article DOI: 10.46654/ij.24889849.b61216

Stock G.N, Greis N.P. and Kasarda J.D. (2000). Enterprise logistics and supply chainstructure: The role of fit. Journal of Operation Management, 18, 531-547.

Szymanski, D. M., \& David H. H. (2001).Customer Satisfaction: A Meta-Analysis of the Empirical Evidence. Journal of the Academy of Marketing Science 29 (1):16-35. 